\title{
Citron Binds to PSD-95 at Glutamatergic Synapses on Inhibitory Neurons in the Hippocampus
}

\author{
Wandong Zhang, Luis Vazquez, Michelle Apperson, and Mary B. Kennedy \\ Division of Biology, California Institute of Technology, Pasadena, California 91125
}

Synaptic NMDA-type glutamate receptors are anchored to the second of three PDZ (PSD-95/Discs large/ZO-1) domains in the postsynaptic density (PSD) protein PSD-95. Here, we report that citron, a protein target for the activated form of the small GTP-binding protein Rho, preferentially binds the third PDZ domain of PSD-95. In GABAergic neurons from the hippocampus, citron forms a complex with PSD-95 and is concentrated at the postsynaptic side of glutamatergic synapses. Citron is expressed only at low levels in glutamatergic neurons in the hippocampus and is not detectable at synapses onto these neurons. In contrast to citron, p135 SynGAP, an abundant synaptic Ras GTPase-activating protein that can bind to all three PDZ domains of PSD-95, and $\mathrm{Ca}^{2+} /$ calmodulindependent protein kinase II (CaM kinase II) are concentrated postsynaptically at glutamatergic synapses on glutamatergic neurons. CaM kinase II is not expressed and p135 SynGAP is expressed in less than half of hippocampal GABAergic neurons.

Segregation of citron into inhibitory neurons does not occur in other brain regions. For example, citron is expressed at high levels in most thalamic neurons, which are primarily glutamatergic and contain CaM kinase II. In several other brain regions, citron is present in a subset of neurons that can be either GABAergic or glutamatergic and can sometimes express CaM kinase II. Thus, in the hippocampus, signal transduction complexes associated with postsynaptic NMDA receptors are different in glutamatergic and GABAergic neurons and are specialized in a way that is specific to the hippocampus.

Key words: citron; PSD-95; inhibitory neurons; postsynaptic density; synaptic transmission; signal transduction
Glutamate is the principal excitatory transmitter in the vertebrate brain. Our laboratory is interested in understanding the organization of signaling complexes at glutamatergic synapses. We have identified several proteins associated with the postsynaptic density (PSD), a filamentous cytosolic structure attached to the postsynaptic membrane of excitatory glutamatergic synapses in the CNS. One of these is the scaffold protein PSD-95 (Cho et al., 1992; Hunt et al., 1996; Kennedy, 1997), which is believed to attach NMDAtype glutamate receptors to internal signaling molecules at the synapse (Kornau et al., 1995; Niethammer et al., 1996). Other proteins of the PSD-95 family, including PSD-93/Chapsyn, SAP102 (synapse-associated protein), and hDLG/SAP97, are present at distinct but overlapping sets of synapses in the CNS (Cho et al., 1992; Kistner et al., 1993; Muller et al., 1995; Brenman et al., 1996; Hunt et al., 1996; Laube et al., 1996; Muller et al., 1996). These proteins belong to the membrane-associated guanylate kinase (MAGUK) family, which includes other intercellular junctional proteins, such as ZO-1 in tight junctions and dlg-A in Drosophila septate junctions (Woods and Bryant, 1991; Willott et al., 1993). MAGUKs all contain three NH2-terminal PDZ (PSD-95/Discs large/ZO-1) domains, an $\mathrm{SH} 3$ domain, and a $\mathrm{COOH}$-terminal guanylate kinase domain that is enzymatically inactive but may serve as a protein interaction motif (Kim et al., 1997). The first and

\footnotetext{
Received Aug. 25, 1998; revised Oct. 8, 1998; accepted Oct. 20, 1998.

This work was supported by United States Public Health Service Grant NS28710 and National Science Foundation Grant GER-9023446. We thank Leslie Schenker for preparation of cultures and help with experiments, Hans-Christian Kornau and Peter Seeburg for the PSD-95 fragment library, Dr. Susan Catalano for help with preparation of the figures, and Kathleen Branson for help with preparation of this manuscript.

Correspondence should be addressed to Mary B. Kennedy, Division of Biology 216-76, California Institute of Technology, Pasadena, CA 91125.

Copyright (C) 1998 Society for Neuroscience $\quad 0270-6474 / 98 / 190096-13 \$ 05.00 / 0$
}

second PDZ domains of PSD-95 may participate in the clustering of NMDA-receptors at vertebrate glutamatergic synapses and of $\mathrm{K}^{+}$channels at cerebellar pinceau junctions and Drosophila neuromuscular junctions via interaction with a short $\mathrm{COOH}$-terminal sequence, the tS/TXV (terminal S/TXV) motif (Kim et al., 1995; Kornau et al., 1995; Niethammer et al., 1996; Tejedor et al., 1997). These findings have led to the hypothesis that PSD-95 and its relatives act as molecular scaffolds at the synapse. Indeed, PDZ domain-containing proteins appear to perform a variety of scaffolding functions. Genetic confirmation of this idea comes from work on the InaD mutant of Drosophila melanogaster. The protein encoded by InaD contains five PDZ domains and anchors the light-activated TRP ion channel in a complex with its effector proteins phospholipase $\mathrm{C} \beta$ (Chevesich et al., 1997; Tsunoda et al., 1997) and protein kinase C (Tsunoda et al., 1997).

A variety of proteins that interact with protein-binding domains in PSD-95 have been identified. These include GKAP (guanylate kinase domain-associated protein) (Kim et al., 1997) and neuroligin (Irie et al., 1997) and CRIPT (Niethammer et al., 1998), which interact with the third PDZ domain. SynGAP, a Ras GTPase activating protein, is nearly as abundant in the PSD fraction as PSD-95 itself (Chen et al., 1998) and can associate with all three of the PDZ domains in PSD-95 (Kim et al., 1998). SynGAP can be phosphorylated by $\mathrm{Ca}^{2+} /$ calmodulin-dependent protein kinase II (CaM kinase II) in the PSD fraction and its GAP activity is reduced after phosphorylation (Chen et al., 1998). Thus, SynGAP and CaM kinase II constitute a signal transduction complex associated with the NMDA receptor.

Here, we describe an additional signaling molecule that interacts with PSD-95 at synapses. Citron was first identified in a yeast two-hybrid screen for proteins that interact with the activated form of Rho GTPase (Madaule et al., 1995) and is a brain specific 


\begin{tabular}{lc}
\hline Table 1. Amino acid sequences of four tryptic peptides \\
Peptide & Amino acid sequence \\
\hline Peptide 1 & VITDLEEQLNQLTEDNAELNXQ \\
Mouse citron 523-542 & VITDLEEQLNQLTEDNAELNNQ \\
Peptide 2 & FYLETQAGKLEAQNR \\
Mouse citron $399-414$ & FYLETQAGKLEAQNR \\
Peptide 3 & LTQGLXEALDRDLLKTER \\
Mouse citron $755-774$ & | | | | | | | | | | | | | | | | | | | | | | \\
Peptide 4 & LTQGLQEALDRADLLKTER \\
Mouse citron 755-771 & LTQGLXEALDRADLLK \\
\end{tabular}

$\overline{\text { Amino acid sequences of four tryptic peptides purified from a digest of PSD-up180 }}$ from rat PSD fraction (Moon et al., 1994; Apperson et al., 1996) are identical to mouse citron (Madaule et al., 1995). Ambiguities in the original peptide sequences are denoted by X. Each original peptide sequence is aligned with the corresponding numbered sequence from mouse citron.

splice variant of citron kinase, a Rho effector expressed in several tissues other than brain (Madaule et al., 1998). We show that in cultured hippocampal GABAergic neurons citron is expressed at high levels and is concentrated at postsynaptic sites in association with PSD-95; however, it is not expressed at high levels in hippocampal glutamatergic neurons. In contrast, the $\alpha$-subunit of CaM kinase II is expressed only in glutamatergic neurons (Jones et al., 1994; Sik et al., 1998). In cultured hippocampal neurons, SynGAP is expressed at high levels in glutamatergic neurons and is undetectable in most, but not all, inhibitory neurons.

PSD-95 appears to act as a scaffolding molecule and can associate with several proteins that possess a tS/TXV motif at their carboxyl end, including the NMDA receptor. At glutamatergic synapses, it forms functional complexes of signaling molecules anchored to NMDA receptors (Kornau et al., 1997). Our results support the idea that the signaling complexes formed by PSD-95 at glutamatergic synapses are determined in part by the complement of PDZ-interacting proteins expressed in the postsynaptic neuron. Interestingly, citron and $\mathrm{CaM}$ kinase II are strictly segregated between glutamatergic and GABAergic neurons in the hippocampus but not in other brain regions. Therefore, the composition of postsynaptic signal transduction complexes at glutamatergic synapses can differ among neurons of otherwise similar cell types that are situated in different brain regions.

A complementary study, "Citron, a Rho-Target, Interacts with PSD-95/SAP-90 at Glutamatergic Synapses in the Thalamus, by Furuyashiki et al. appears in this issue on pages 109-118.

\section{MATERIALS AND METHODS}

Purification of citron from the PSD fraction. Purification from the PSD fraction of a protein band containing a mixture of densin-180 and citron was performed as described by Apperson et al. (1996). Briefly, the PSD fraction was prepared as described previously (Cho et al., 1992) and extracted with $1 \% \mathrm{~N}$-octyl glucoside at $4^{\circ} \mathrm{C}$ for $30 \mathrm{~min}$. The insoluble pellet was treated with a mixture of endoglycosidase $\mathrm{F}$ and $\mathrm{N}$-glycosidase F to shift the mobility of copurifying NR2B. The protein band termed previously PSD-up180 (Moon et al., 1994) was cut from the gels. Proteins contained in the band were electroeluted, transferred to nitrocellulose, and trypsinized. The tryptic peptides were fractionated on $\mathrm{C} 4$ and $\mathrm{C} 18$ HPLC columns. Seven pure peptide peaks were collected and sequenced by gas phase sequencing. Three of the peptide sequences are contained in densin-180 (Apperson et al., 1996). The other four (Table 1) match the sequence of mouse citron (Madaule et al., 1995).

Molecular cloning of rat citron. Two oligonucleotides, 5'-TCGG
ATCCGGAAAGCTGGAGGCCCAA/GAA-3' and 5'-TCGGATCCC TCCTCCAGGTCGGTIATIAC-3', were designed to encode two of the HPLC tryptic peptides identical to mouse citron (peptide 2 and peptide 1) (Table 1). A PCR fragment encoding part of rat citron was amplified by reverse transcription-PCR of rat forebrain poly(A) RNA with the two primers. The fragment was used to screen a $\lambda$ phage cDNA library of rat brain (Clontech, Palo Alto, CA). Four overlapping clones that together encode the entire length of rat citron were isolated and sequenced, and the combined sequences were deposited in the GenBank database (accession number AF 039218).

Antibodies. A peptide, QGLQEALDRADLLKTERC, was synthesized by the California Institute of Technology Microchemistry Laboratory based on one of the citron peptides purified by HPLC (peptide 3 ) (Table 1). The peptide was conjugated to keyhole limpet hemocyanin and was used as antigen to immunize rabbits (Cocalico Biologicals, Inc). Antisera termed CT261 and CT262 obtained from these rabbits were used for Western blots at 1:1000 dilution.

A cDNA fragment encoding the $\mathrm{C}$-terminal 144 residues of citron was cloned into the vector pGEX5X3 (Pharmacia, Piscataway, NJ). The resulting glutathione $S$-transferase (GST) fusion protein was expressed in Escherichia coli $\mathrm{DH} 5 \alpha$. The fusion protein was affinity purified on glutathione-agarose beads, fractionated by SDS-PAGE, electroeluted from gel pieces as described previously (Moon et al., 1994), and used to immunize mice to produce polyclonal ascites fluid (ascites 3A) as described previously (Ou et al., 1993) and to immunize rabbits to obtain polyclonal antiserum CT295 (Cocalico). A second cDNA fragment encoding residues 326-918, which comprise approximately two-thirds of the coiled-coil domain of citron, was inserted into pGEX5X3. The GST fusion protein encoded by this construct was expressed in E. coli DH5 $\alpha$, concentrated, and affinity purified on glutathione-agarose beads as described above. The fusion protein was then used to immunize mice to produce polyclonal ascites fluid (ascites 1B).

Rabbit polyclonal antisera against nonphosphorylated CaM kinase II was raised and purified as described by Patton et al. (1993). The purified antiserum recognizes both the $\alpha$ and $\beta$ subunits of CaM kinase II (Patton et al., 1993). Because $75-95 \%$ of the kinase is nonphosphorylated in rat brain (Molloy and Kennedy, 1991), the qualitative staining pattern is the same as the pattern for total CaM kinase II. Mouse monoclonal antibody 6G9 against the $\alpha$ subunit of CaM kinase II was obtained as described previously (Erondu and Kennedy, 1985). Rabbit polyclonal antisera against glutamic acid decarboxylase (GAD)-67 was purchased from Chemicon (Temecula, CA). Antibodies were visualized with fluoresceinconjugated goat anti-rabbit IgG (ICN Biochemicals, Costa Mesa, CA) or $\mathrm{Cy} 3$ conjugated goat anti-mouse $\mathrm{IgG}$ (Chemicon).

Immunoblots. Immunoblots of subcellular fractions (see Fig. 2) were performed as described previously (Cho et al., 1992), with anti-citron serum (CT261) diluted 1:1000. Immunoblots of $100 \mu \mathrm{g}$ of rat forebrain homogenate (see Fig. 7) were performed with ascites 1B at a dilution of 1:500 as described previously (Cho et al., 1992). Bound antibodies were visualized by incubation with goat anti-mouse secondary antibody coupled to alkaline phosphatase. To preadsorb the antisera with its antigen, ascites $1 \mathrm{~B}$ was mixed with the GST fusion protein at a molar ratio of $1: 3$ overnight at $4^{\circ} \mathrm{C}$. Preabsorption with antigen eliminated the staining of citron on immunoblots of brain tissue and in fixed brain sections (see Fig. 7).

Yeast two-hybrid tests. Four different portions of the cDNA encoding citron were amplified by PCR: C-terminal residues 1476-1619, 1476$1612,1589-1619$, and $1589-1612$. The four cDNA fragments were cloned into the pAS2-1 vector (bait vector; Clontech) to generate pAS2-1/1, pAS2-1/2, pAS2-1/3 and pAS2-1/4, respectively, encoding fusion proteins with each of the four sequences and the GAL4 DNA binding domain. PSD-95 cDNA was cloned into the pACT2 vector (prey vector) to generate a fusion protein with the GAL4 DNA activation domain. The ability of the $\mathrm{C}$ terminus of citron to bind to PSD-95 was tested directly by yeast two-hybrid assay in Y187 cells cotransformed with pAS2-1/1 and pACT2/PSD-95. To identify the portion of the C-terminal tail of citron that is necessary for interaction with PSD-95, pAS2-1/2, pAS2 $-1 / 3$, and pAS2-1/4 were cotransformed with pACT2/PSD-95 into Y187. Interaction between proteins encoded by bait and prey vectors was assessed by the formation of blue colonies after incubation with X-gal on filter paper according to the instructions of the supplier (Clontech). To identify the region of PSD-95 that interacts with the citron $\mathrm{C}$ terminus, a fragment library of PSD-95 in the pGAD GH vector (a prey vector), kindly provided by Hans-Christian Kornau and Peter Seeburg (Max Planck Institute for Medical Research, Heidelberg, Germany), was 

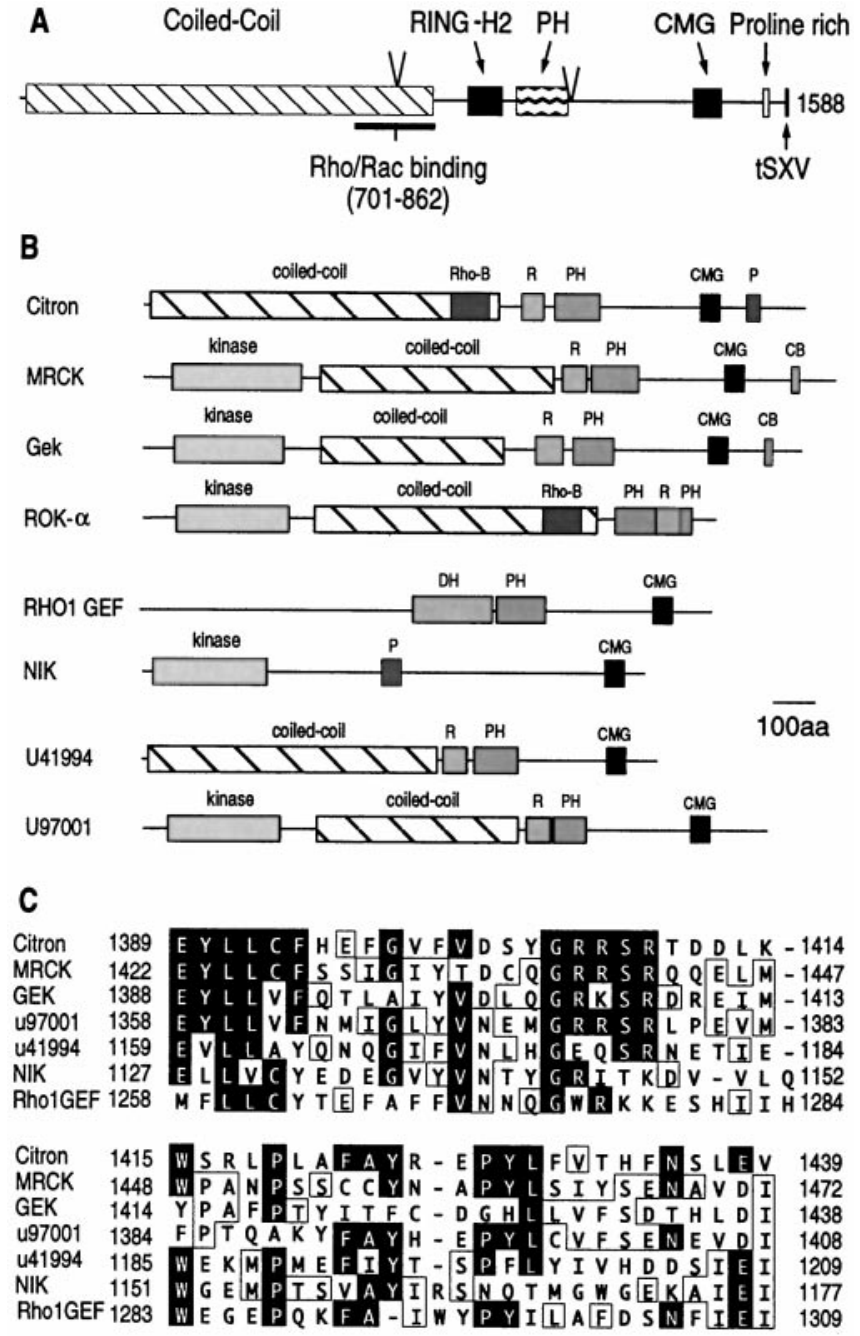

Figure 1. Sequences related to citron. $A$, Domain structure of citron. Ring-H2, Ring-H2 finger domain; $P H$, pleckstrin homology domain; $C M G$, citron/MRCK/Gek domain; $t S X V$, terminal S/TXV motif predicted to bind PDZ domains. The structures of cDNAs reveal two apparent alternative splice sites where two 15 residue sequences can be inserted (indicated by $V$ ). $B$, Proteins related to citron. A family of proteins that are effectors for the $\mathrm{Rho} / \mathrm{Rac} / \mathrm{Cdc} 42$ GTPases have domain structures similar to citron (see Results). MRCK, Myotonic dystrophy kinase-related kinase; GEK, Genghis Khan; ROK- $\alpha$, Rho-associated kinase; RHO1 $G E F$, Rho-1 guanine nucleotide exchange factor; NIK, NCK-interacting kinase. $C$, Alignment of sequences in putative $C M G$ domain. Sequences range from 26 to $43 \%$ identical to citron. Black boxes indicate four or more identities to citron. Open boxes indicate other identities.

screened with pAS2-1/1 as bait. Positively interacting cDNA clones were isolated and sequenced as described previously (Kornau et al., 1995).

Coimmunoprecipitation. PSD fraction $(150 \mu \mathrm{g})$ extracted once with Triton X-100 (Cho et al., 1992) was solubilized by a 10 min incubation at room temperature in 2\% SDS in immunoprecipitation (IP) buffer [137 mM NaCl, $2.7 \mathrm{~mm} \mathrm{KCl}, 4.3 \mathrm{~mm} \mathrm{Na} \mathrm{HPO}_{4}, 1.4 \mathrm{~mm} \mathrm{KH}_{2} \mathrm{PO}_{4}, 5 \mathrm{~mm}$ EDTA, 5 mm EGTA, 1 mm Na $\mathrm{VO}_{4}$, $10 \mathrm{~mm} \mathrm{NaPPi}, 50 \mathrm{~mm} \mathrm{NaF}, 0.1 \mathrm{~mm}$ phenylmethylsulfonyl fluoride, and $1 \times$ protease inhibitor cocktail (Boehringer Mannheim, Indianapolis, IN)]. After solubilization, the mixture was diluted with 5 vol ice-cold $2 \%$ Triton X-100 in IP buffer as described previously (Lau et al., 1996). The mixture was incubated with $8 \mu \mathrm{l}$ of anti-citron serum (CT295), $8 \mu \mathrm{l}$ of anti-NR2B serum (Violet) or $8 \mu \mathrm{l}$ of preimmune serum from the rabbit producing CT295, and $50 \mu \mathrm{l}$ of Protein A-Sepharose (1:1 slurry) overnight at $4^{\circ} \mathrm{C}$. The Protein A-Sepharose complex was washed once with $1 \%$ Triton X-100 and three times with IP buffer. Precipitated proteins were eluted from Protein A-Sepharose into SDS-PAGE sample buffer, fractionated by SDS-PAGE,

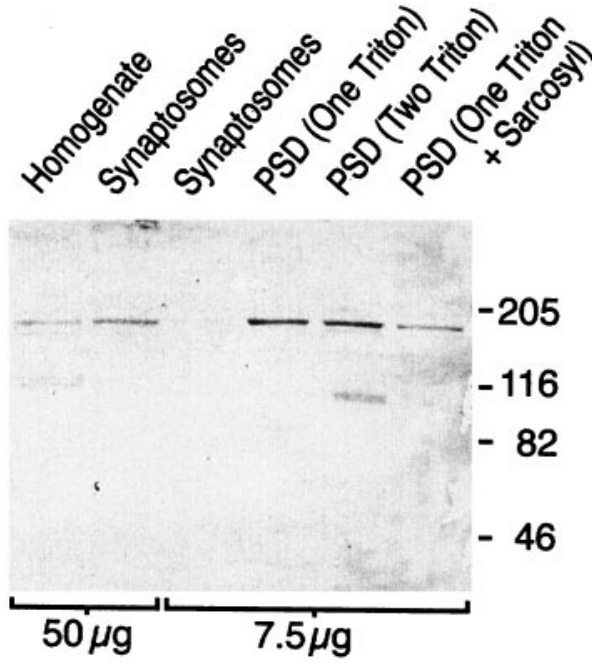

Figure 2. Enrichment of citron in PSD fractions. Immunoblots of PSDs prepared by extraction with the indicated detergents were prepared and labeled with anti-citron antibody as described in Materials and Methods. Lane 1, Rat forebrain homogenate $(50 \mu \mathrm{g})$; lane 2, synaptosomes $(50 \mu \mathrm{g})$; lane 3, synaptosomes $(7.5 \mu \mathrm{g})$; lane 4 , PSD fraction extracted once with $0.5 \%$ Triton X-100 $(7.5 \mu \mathrm{g})$; lane 5, PSD fraction extracted twice with $0.5 \%$ Triton X-100 $(7.5 \mu \mathrm{g})$; lane 6 , PSD fraction extracted once with $0.5 \%$ Triton X-100, followed by $3 \%$ sarcosyl $(7.5 \mu \mathrm{g})$. Molecular weight markers are shown on the right.

and visualized by Western blot with anti-citron serum (CT261) diluted 1:1000, anti-NR2B serum diluted 1:1000, anti-PSD-95 monoclonal 7E3 diluted 1:1000, or anti- $\alpha \mathrm{CaM}$ kinase II (6G9) diluted 1:500 as described previously (Cho et al., 1992).

Immunocytochemical labeling of dissociated cultures of hippocampal neurons. Cultures of dissociated hippocampal neurons were prepared from embryonic day 18 rats and grown for $3-5$ weeks in vitro as described previously (Brewer et al., 1993). Coverslips containing the cultured cells were removed from wells for immunostaining, and the cells were fixed in $-20^{\circ} \mathrm{C}$ methanol. Immunolabeling was performed as described previously (Apperson et al., 1996). Anti-citron antibodies (ascites 3A or CT295) were diluted 1:500. Preadsorption of the antibodies with antigen entirely blocked staining. For double-labeling experiments, mouse monoclonal anti-PSD-95 (6G6) (Cho et al., 1992) was diluted 1:1000, rabbit anti-NR2B antiserum (Xandria) (Kornau et al., 1995) was diluted 1:200, and mouse monoclonal anti-CaM kinase II antibody (6G9) (Erondu and Kennedy, 1985) was used at $20 \mu \mathrm{g} / \mathrm{ml}$. Mouse anti-SynGAP ascites antibodies (anti-GAP) (Chen et al., 1998) were diluted 1:500.

We used an antibody against GAD as a marker for GABAergic neurons. For double-labeling experiments with this antibody, cells were fixed in $4 \%$ paraformaldehyde and labeled as described previously (Craig et al., 1994). Rabbit polyclonal anti-GAD antibody (Chemicon) was diluted 1:1000, and mouse anti-citron antibody (ascites 1B) was diluted 1:300.

Antibodies were labeled with fluorescein-conjugated goat anti-rabbit IgG (Cappel, West Chester, PA) or Cy3 conjugated goat anti-mouse IgG (Chemicon) diluted 1:100. Coverslips were mounted on glass slides and viewed in a Zeiss (Oberkochen, Germany) LSM310 fluorescence laserscanning confocal microscope with a $63 \times$ oil immersion objective at zoom setting 1 or 2 .

Immunocytochemistry of tissue sections. Sprague Dawley rats (6- to 8 -week-old) were perfused transcardially under Nembutal anesthesia with PBS (0.9\% NaCl and $0.02 \mathrm{M} \mathrm{NaPO} 4, \mathrm{pH} 7.4)$ for a few seconds and then with $500 \mathrm{ml}$ of $4 \%$ paraformaldehyde in $0.1 \mathrm{M} \mathrm{NaPO} 4, \mathrm{pH}$ 7.4. The head was cooled on ice for $20 \mathrm{~min}$, and then the brain was removed and sectioned into $50 \mu \mathrm{m}$ coronal or sagittal sections in cold PBS on a vibratome. Free floating sections were processed essentially as described by De Camilli et al. (1983). They were permeabilized with 3\% Triton $\mathrm{X}-100$, treated with $0.1 \mathrm{M}$ glycine in PBS, and then preincubated with preblock buffer (5\% normal goat serum, $0.45 \mathrm{M} \mathrm{NaCl}$, and $20 \mathrm{mM} \mathrm{NaPO}_{4}$, $\mathrm{pH}$ 7.4). Sections were incubated overnight at $4^{\circ} \mathrm{C}$ in ascites $1 \mathrm{~B}(1: 100)$, anti-GAD-67 (1:1000), or anti-CaM kinase II antiserum (1:200) in pre- 


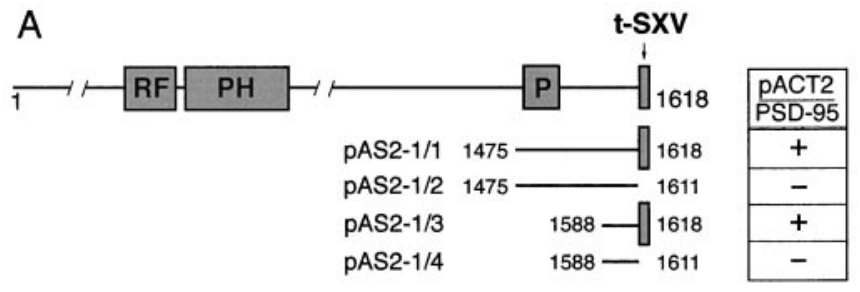

B

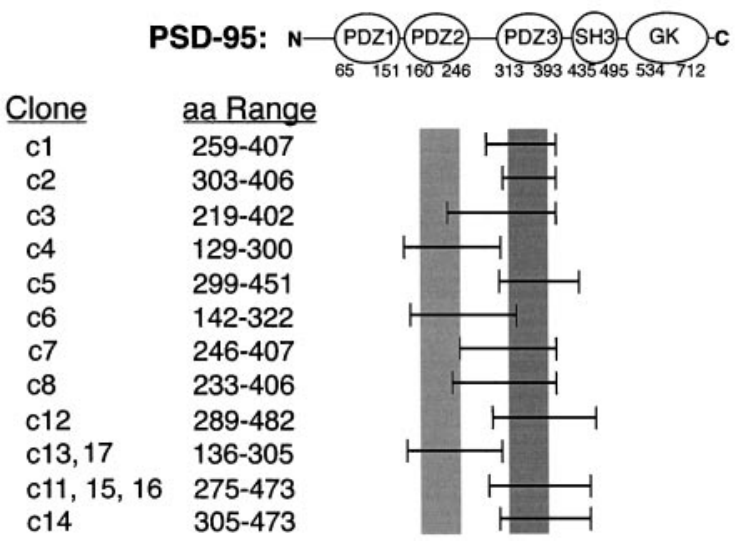

Figure 3. Yeast two-hybrid assay for interaction of citron and PSD-95. A, Segments of cDNA encoding the portions of the citron $\mathrm{C}$ terminus indicated in the figure were inserted into the yeast pAS2-1 vector and tested in the two-hybrid assay for interaction with PSD-95. Full-length cDNA encoding PSD-95 was inserted in the pACT2 vector. Interaction and no interaction is indicated by + and - , respectively. $B$, A fragment mini-library of PSD-95 constructed in the prey vector pGADGH (Kornau et al., 1995) was screened with the bait vector pAS2-1/1 described in $A$. Clones encoding interacting segments of PSD-95 were isolated and sequenced as described in Materials and Methods. Nine positive clones encoded PDZ3, and three positive clones encoded PDZ2 of PSD-95.

block buffer. Sections were then washed three times for 15 min each in preblock buffer and incubated for $1 \mathrm{hr}$ at room temperature in fluorescein-conjugated goat anti-rabbit or Cy3-conjugated goat antimouse IgG diluted 1:100 in preblock buffer. The sections were washed once in preblock buffer, rinsed twice in PBS, post-fixed in $2 \%$ paraformaldehyde for $10 \mathrm{~min}$, and mounted on slides in $80 \%$ glycerol, $0.4 \%$ $p$-phenylenediamine, and $0.1 \mathrm{M} \mathrm{NaCO}_{3}, \mathrm{pH} 9.25$. The sections were viewed in a Zeiss LSM 310 laser-scanning confocal microscope with $10 \times$, $20 \times, 40 \times(1.3 \mathrm{NA})$, or $63 \times(1.4 \mathrm{NA})$ objectives.

Miscellaneous methods. Protein was measured by the method of Peterson (1983). Forebrain homogenates, synaptosomes, and PSD fractions extracted with different detergents were prepared as described by Cho et al. (1992).

\section{RESULTS}

\section{Identification of citron in PSD fraction}

To gain insight into the molecular organization of the glutamatergic postsynaptic signaling machinery, we have sequenced and cloned proteins that are abundant in isolated PSDs (Kennedy, 1993, 1997). Proteins in a band of $\sim 180 \mathrm{kDa}$ were purified from the PSD fraction by SDS-PAGE (Apperson et al., 1996; Moon et al., 1994). Seven peptides from the trypsinized protein band were purified by HPLC and sequenced by gas phase Edman degradation. Three of the seven peptides were present in densin-180, a postulated synaptic adhesion molecule (Apperson et al., 1996). A BLAST search of the GenBank database revealed that the remaining four peptide sequences (Table 1) are present in a protein named citron previously identified in mouse by the yeast twohybrid method as a GTP-Rho binding partner and proposed to be a Rho/Rac effector (Madaule et al., 1995). Citron interacts with the GTP-bound forms of Rho and Rac1, but not with $\mathrm{Cdc} 42$ (Madaule et al., 1995). It contains a long N-terminal region that is predicted to form a coiled-coil and includes the Rho-binding motif. This domain is followed by a ring finger motif, a $\mathrm{PH}$ domain, a proline-rich region, and a tS/TXV motif (Madaule et al., 1995) (Fig. 1). We isolated the cDNA encoding rat citron and found that the encoded protein is $\sim 98 \%$ identical to mouse citron. Analysis of several overlapping cDNA clones and comparison with the mouse sequence suggests the presence of alternatively spliced variants containing inserts 1 and 2 (Fig. 1). The rat sequences are deposited in the GenBank database (accession number AF 039218).

The BLAST search revealed a human DNA (clone 127H14) in the expressed sequence tag (EST) database, which is $95 \%$ similar to mouse citron, as well as several proteins containing domains with sequence similarity to citron. Some of these comprise an apparent family of protein serine/threonine kinases with an arrangement of downstream domains very similar to that of citron,

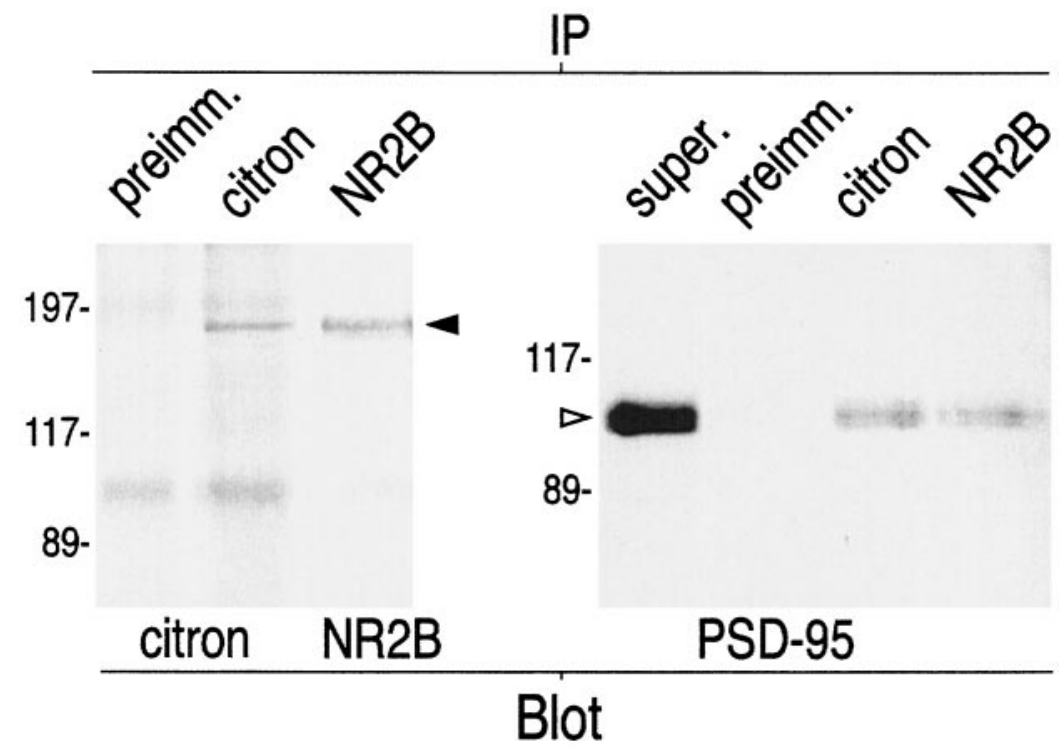

Figure 4. Coimmunoprecipitation of citron and PSD-95 from rat brain. Aliquots of rat brain PSD fraction $(150 \mu \mathrm{g}$ in $600 \mu \mathrm{l})$, prepared as described in Materials and Methods, were mixed with $8 \mu \mathrm{l}$ of antiserum against citron, $8 \mu \mathrm{l}$ of antiserum against NR2B, or $8 \mu \mathrm{l}$ of preimmune serum. Immune complexes were purified on agarose beads coupled to Protein A-Sepharose and fractionated by SDS-PAGE on $7.5 \%$ gels. Proteins were transferred to nitrocellulose and blotted with the indicated antisera as described in Materials and Methods. super., The supernatant ( $1 / 30 \mathrm{vol})$ from immunoprecipitation by antibodies against citron. (The supernatant from immunoprecipitation by antibodies against NR2B appeared identical.) No citron was detected in the supernatant from immunoprecipitation with anti-citron antibody. Positions of molecular weight markers are indicated on the left. 

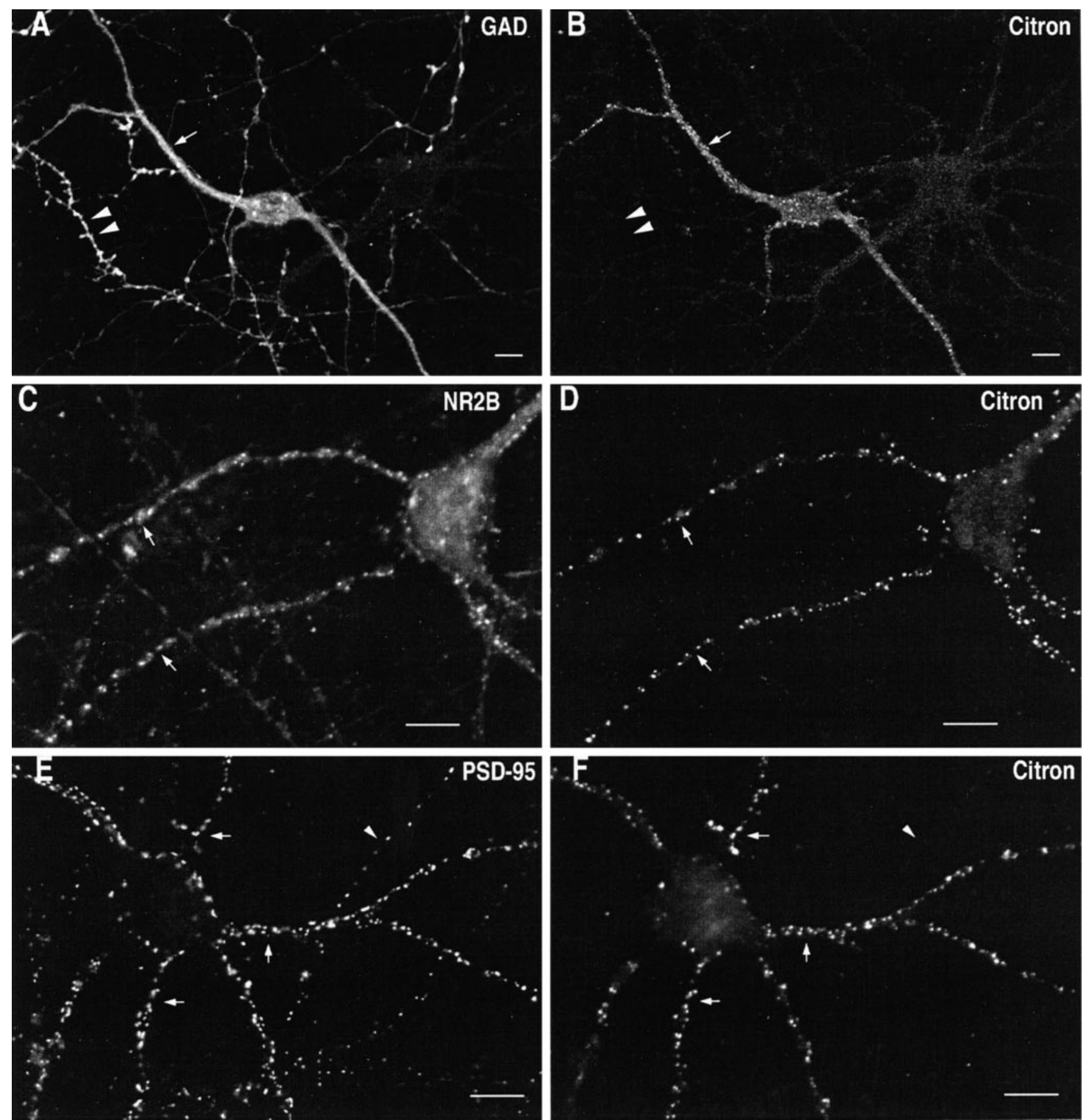

Figure 5. Immunofluorescent labeling of citron, GAD, NR2B, and PSD-95 in cultures of dissociated hippocampal neurons. Cultures were grown and labeled with antibodies against the indicated proteins as described in Materials and Methods. $A, B$, A neuron double stained for GAD $(A)$ and citron (B). Citron stains dendrites and somas (arrow) but not axons (double arrowhead) of $>90 \%$ of neurons that are stained with anti-GAD antibody. $\mathrm{GAD} /$ citron-positive neurons comprise $7-10 \%$ of neurons in the cultures. $C, D$, A neuron double stained for NR2B $(C)$ and citron $(D)$. Punctate labeling by antibody against citron along dendrites in this neuron (arrows) colocalizes with labeling by antibody against NR2B. E, $F$, A neuron double stained for PSD-95 $(E)$ and citron $(F)$. Punctate labeling by antibody against citron along dendrites of this neuron (arrows) colocalizes with labeling by antibody against PSD-95. Some anti-PSD-95-labeled puncta do not contain citron (arrowhead). Many of these appear to arise from a neighboring citron-negative neuron. Scale bars, $10 \mu \mathrm{m}$.

including coiled-coil regions, a ring finger domain, and a $\mathrm{PH}$ domain (Fig. 1B). Myotonic dystrophy kinase-related kinase (MRCK) and MRCK- $\beta$ are related to the myotonic dystrophy kinase (Leung et al., 1998). Genghis Khan (Gek) is a Drosophila protein kinase that is believed to be a Cdc42 effector (Luo et al., 1997). A predicted protein serine/threonine kinase encoded in the Caenorhabditis elegans genome (GenBank accession number U97001) also appears to be a member of this family, as does Rho-associated kinase (ROK- $\alpha$ ) (Leung et al., 1995), Rho-kinase (Matsui et al., 1996), and p160ROCK (Ishizaki et al., 1996), all of which are effectors for the $\mathrm{Cdc} 42 / \mathrm{Rac} / \mathrm{Rho}$ family.

Residues 1200-1500 in citron are also homologous to se- 

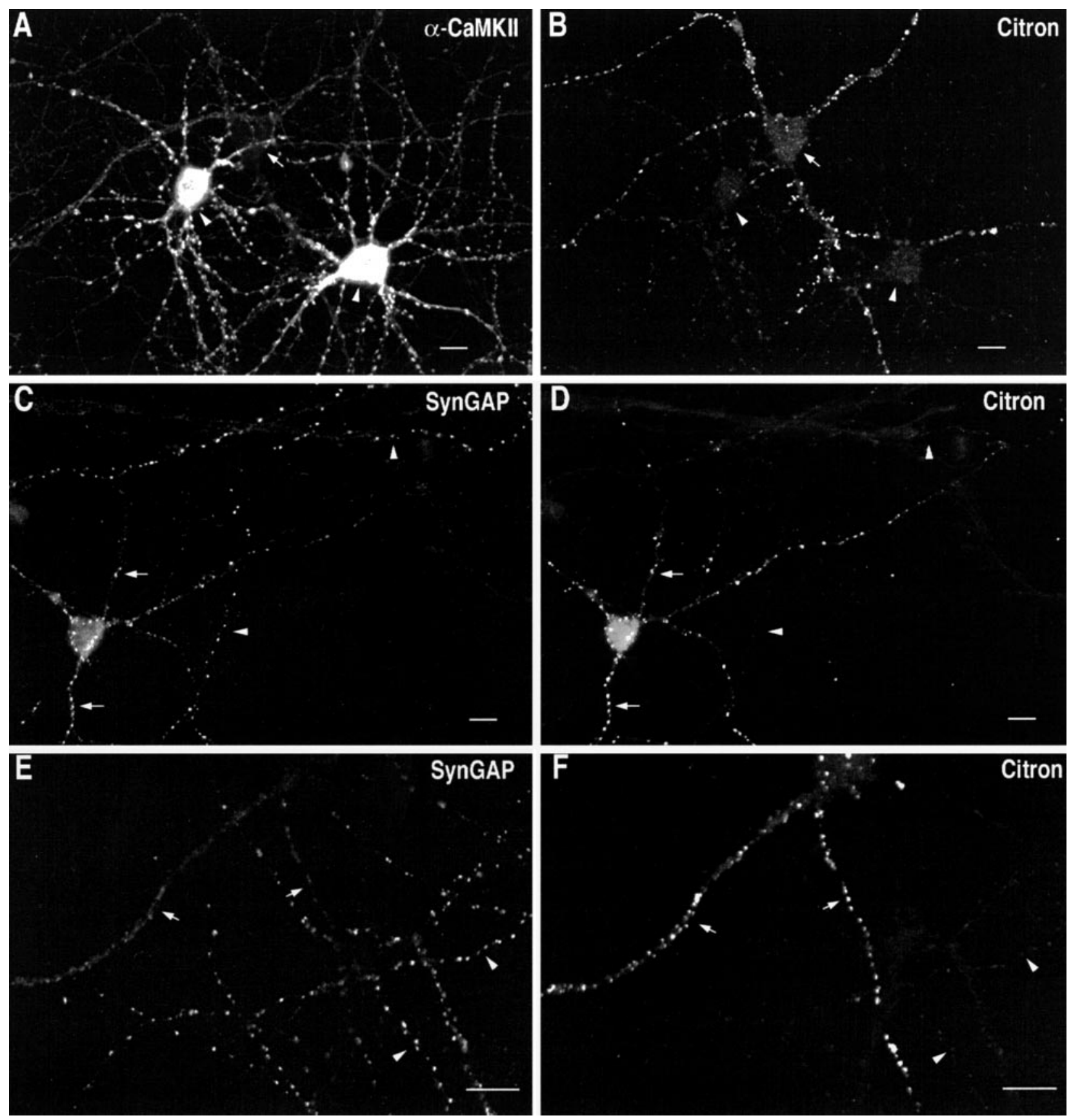

Figure 6. Immunofluorescent labeling of citron, the $\alpha$ subunit of CaM kinase II, and p135 SynGAP in cultures of dissociated hippocampal neurons. $A$, $B$, A field of three neurons double stained for $\alpha \mathrm{CaM}$ kinase II $(A)$ and citron $(B)$. Two neurons (arrowheads) stain positively for $\alpha \mathrm{CaM}$ kinase II, and one (arrow) stains positively for citron. The two proteins are present in distinct sets of neurons. The population of neurons that stain for citron represents $\sim 7-10 \%$ of the total. $C, D$, A field of neurons double stained for SynGAP $(C)$ and citron $(D)$. One neuron (arrows) is labeled by both antisera. Several dendrites in the field (arrowheads) are labeled only by antibody against SynGAP. Less than 20\% of the citron-positive neurons also contain SynGAP. Essentially all of the citron-negative neurons are labeled by SynGAP. $E, F$, A field of dendrites double stained for SynGAP $(E)$ and citron $(F)$. Dendrites that contain only SynGAP are labeled with arrowheads. Dendrites that contain only citron are labeled with arrows. Scale bars, $10 \mu \mathrm{m}$.

quences in two of the protein kinases involved in signal transduction in the Rho/Rac pathway. The similarity is highest (26-43\% identical) in residues 1389-1442 (Fig. 1C) and may define a novel protein domain, which we term a CMG domain (citron/MRCK/ Gek). In addition, the Rho-1 GDP-GTP exchange protein 2 (RholGEF), a predicted C. elegans protein (GenBank accession number U41994), and the NCK-interacting kinase (NIK) contain a CMG domain. The ROK- $\alpha$-related kinases lack the novel CMG domain.

\section{Enrichment of citron in the PSD}

We raised antibodies against rat citron and prepared immunoblots of the subcellular fractions indicated in Figure 2. Citron is $\sim 12-, 13-$, and 7-fold enriched in the one Triton, two Triton, and 

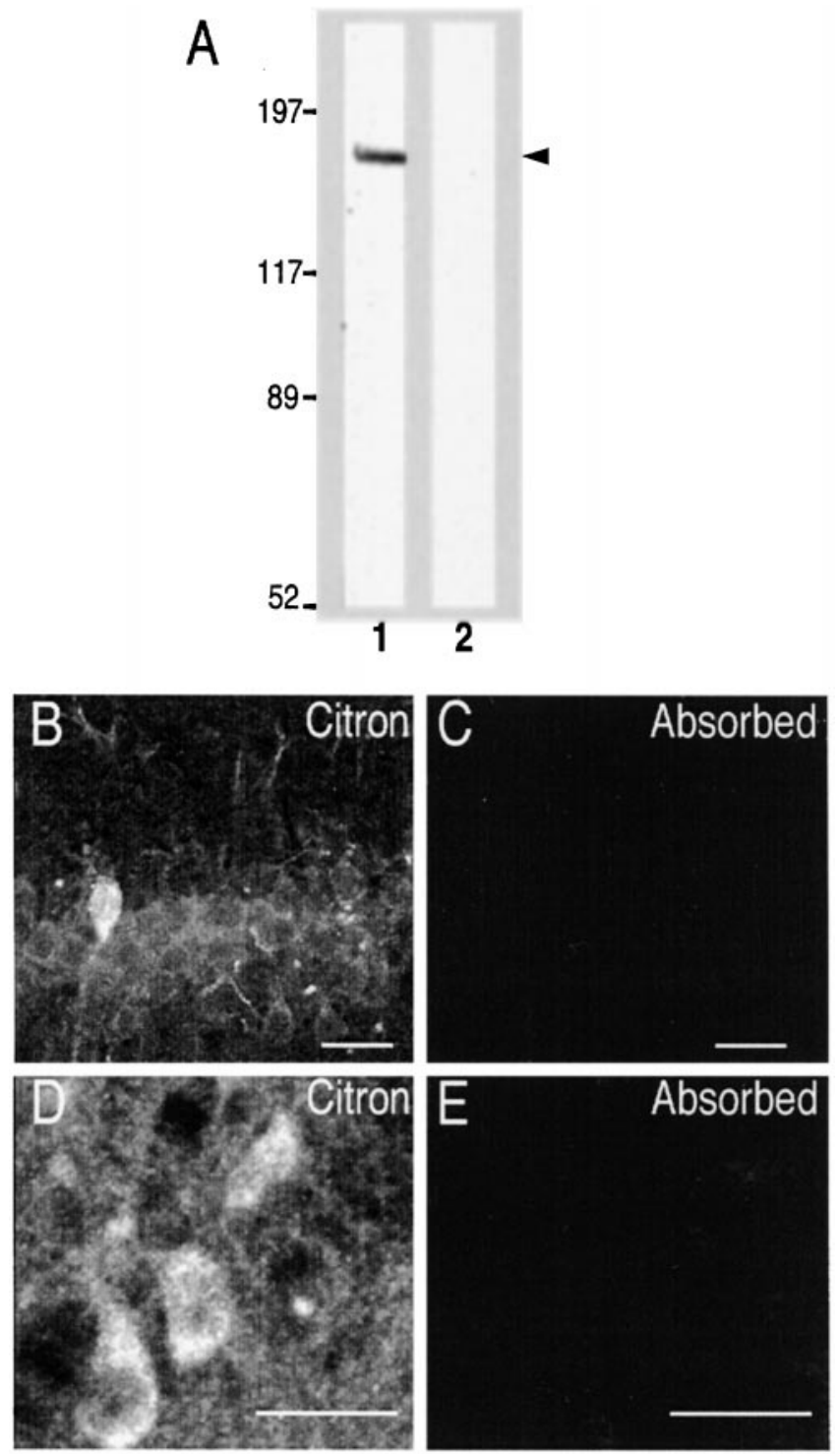

Figure 7. Specificity of antibodies against citron used for immunocytochemistry. $A$, Aliquots of homogenate of rat forebrain $(100 \mu \mathrm{g})$ were fractionated by SDS-PAGE and blotted to nitrocellulose as described in Materials and Methods. The lanes were probed with either ascites 1B against citron (1) or the same amount of ascites $1 \mathrm{~B}$ preabsorbed with antigen (2) as described in Materials and Methods. $B$, $C$, Hippocampal pyramidal layer in area CA1 labeled with anti-citron antisera $(B)$ and a neighboring section labeled with anti-citron antiserum preadsorbed with antigen $(C)$ as described in Materials and Methods (40× lens objective). The sections were photographed at identical microscope settings. $D, E$, Thalamic neurons labeled with anti-citron antisera $(D)$ and a neighboring section labeled with anti-citron antiserum preadsorbed with antigen $(E)$ as described in Materials and Methods ( $40 \times$ lens objective). The sections were photographed at identical microscope settings. Scale bars, $25 \mu \mathrm{m}$.

sarcosyl-extracted PSD fractions, respectively, compared with synaptosomal fractions (Fig. 2), suggesting that citron associates specifically with proteins in the PSD fraction.

\section{Association of citron with PSD-95}

Both mouse and rat citron contain the $\mathrm{COOH}$-terminal sequence QSSV, which fits the tS/TXV motif that binds to certain PDZ domains in PSD-95 (Kornau et al., 1995; Niethammer et al., 1996). Therefore, we used the yeast two-hybrid system to test whether citron binds directly to PSD-95. The results (Fig. 3) show that citron interacts with PSD-95, and this interaction is dependent on the presence of the terminal QSSV. We screened a fragment library of PSD-95 cDNA to determine which domains of PSD-95 interact with citron and found that it can interact with both PDZ2 and PDZ3 of PSD-95 but appears to prefer PDZ3. Nine of 12 interacting clones encode the full PDZ3 domain; the other three encode PDZ2. Niethammer et al. (1998) reported that the C-terminal sequence QTSV in CRIPT is critical for preferential binding to PDZ2 and PDZ3 over PDZ1 of PSD-95. Mutation to QTDV switched the binding specificity to PDZ1 and PDZ2. Additional mutation to $E T D V$, which is identical to the C-terminal sequence of NR2B, enhanced the specificity for PDZ1 and PDZ2. The C-terminal sequence QSSV of citron, which is similar to that of CRIPT, is consistent with its favorable binding to PDZ2 and PDZ3.

To test whether citron associates with PSD-95 in brain tissue, citron was immunoprecipitated from a rat brain PSD fraction (Fig. 4). Citron is present in this fraction at $<20 \%$ of the level of PSD-95 as estimated from Coomassie blue-stained gels. As a positive control, NR2B, which is present in the PSD fraction at approximately the same level as citron, was also immunoprecipitated as described previously (Lau et al., 1996). We did not detect any citron remaining in the supernatant after immunoprecipitation, indicating that precipitation of citron was nearly complete; however, only $\sim 0.3 \%$ of the total PSD-95 was immunoprecipitated (Fig. 4, right, estimated from density of bands on immunoblots). Because detergent must be used to partially disrupt the tight associations among proteins in the PSD-fraction before incubation with antibodies, this experiment does not give quantitative information about the amount of PSD-95 associated with citron in the PSD-fraction or in vivo. Three control experiments, however, support the conclusion that PSD-95 forms a specific complex with citron. First, approximately the same amount of PSD-95 coimmunoprecipitated with citron as with NR2B. Second, the $\alpha$ subunit of CaM kinase II, an abundant protein in the PSD fraction, was not detected in the immunoprecipitates (data not shown). Third, PSD-95 was not immunoprecipitated by preimmune serum from the rabbit producing the anti-citron antibody.

\section{Citron is expressed at glutamatergic postsynaptic sites in GABAergic neurons in hippocampal cultures}

Anti-citron antibodies visualized by fluorescent labeling were used to study the distribution of citron in dissociated hippocampal neurons grown for 3-5 weeks in culture (Fig. 5). We found that citron is expressed most highly in a subpopulation of neurons representing $\sim 7-10 \%$ of the total. We identified the neuronal population expressing high levels of citron as GABAergic neurons by showing that they stain strongly for GAD, a GABAergic marker (Fig. 5A). Citron is expressed at much lower levels within the large population of putative glutamatergic neurons in the cultures and does not appear concentrated in dendrites or synapses of those neurons. Citron is not expressed in glial cells.

In neurons in which citron is highly expressed, dots along dendrites are brightly labeled by the anti-citron antibody. The punctate staining for citron coincides with punctate staining for NR2B (Fig. 5B), suggesting that the puncta are glutamatergic synapses. The punctate staining for citron also colocalizes with that of PSD-95 (Fig. 5C), a marker for glutamatergic postsynaptic sites (Hunt et al., 1996). The staining patterns are consistent with 

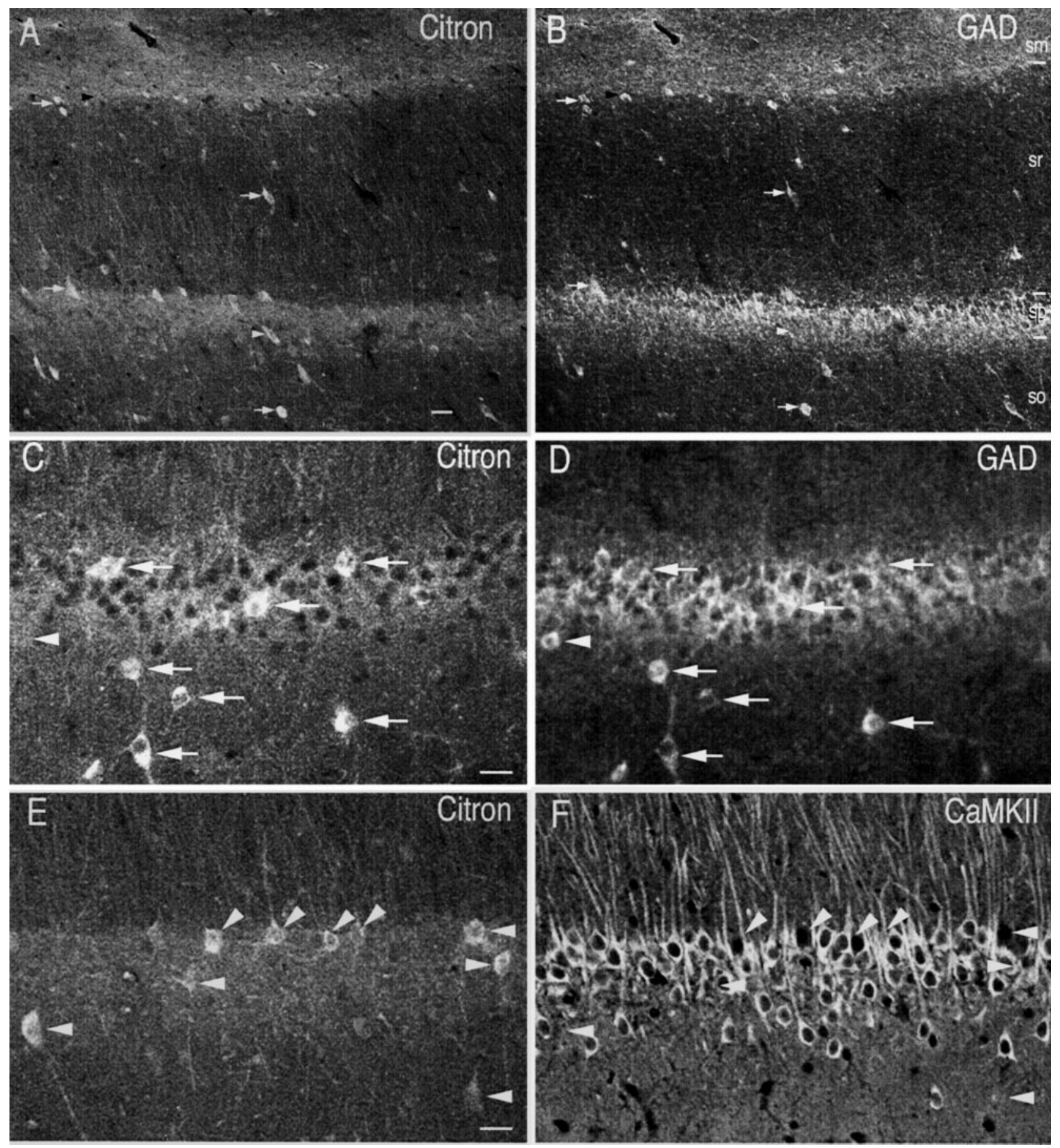

Figure 8. Immunocytochemical colocalization of citron, GAD, and CaM kinase II in hippocampal inhibitory interneurons. Coronal sections were cut from a rat brain fixed by perfusion as described in Materials and Methods. $A, B$, Colocalization of citron and GAD. Area CA1 of the rat hippocampus at approximately bregma -3.3 (Paxinos and Watson, 1998) was double labeled with anti-citron $(A)$ and anti-GAD $(B)$ as described in Materials and Methods $(10 \times$ lens objective). Arrows, Neurons labeled with both antisera; white arrowhead, neuron labeled with anti-citron and not anti-GAD; black arrowhead, neuron labeled with anti-GAD and not anti-citron. $s m$, Stratum moleculare; $s r$, stratum radiatum; $s p$, stratum pyramidale; $s o$, stratum oriens. $C, D$, Colocalization of citron and GAD. Area CA1 of the hippocampus in sections at approximately bregma -3 to -3.5 (Paxinos and Watson, 1998) was double-labeled with antibodies against citron $(C)$ and GAD $(D)$ as described in Materials and Methods (40× lens objective). Arrows, Neurons labeled with both antibodies. $E, F$, Colocalization of citron and CaM kinase II. Area CA1 of the rat hippocampus in sections at approximately bregma -3 to -3.5 (Paxinos and Watson, 1998) was double labeled with anti-citron $(E)$ and anti-CaM kinase II $(F)$ as described in Materials and Methods (40X lens). Arrowheads, Neurons labeled with anti-citron antibodies and devoid of labeling with anti-CaM kinase II antibodies. Scale bars, $25 \mu \mathrm{m}$. 

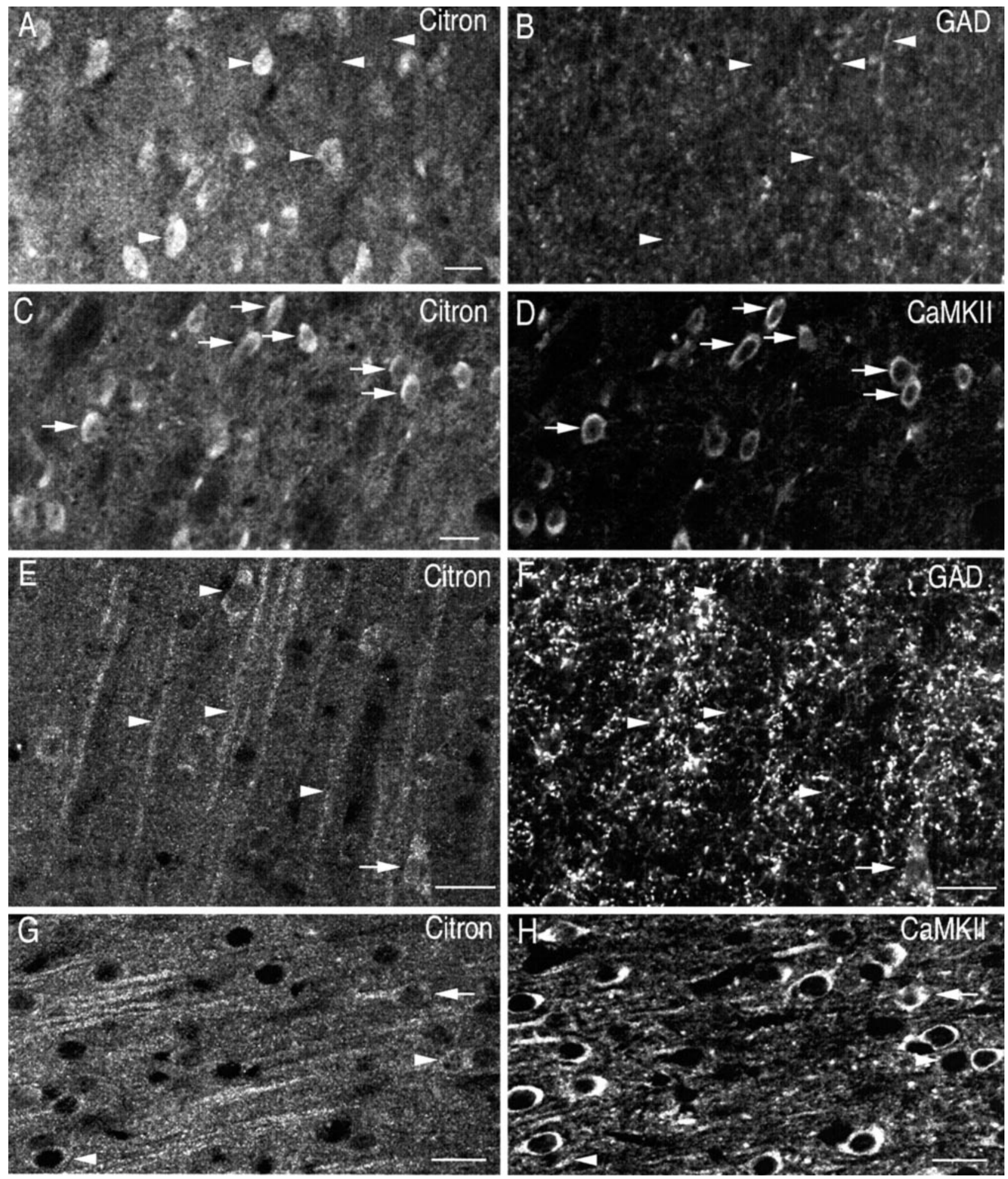

Figure 9. Immunocytochemical localization of citron, GAD, and CaM kinase II in thalamus and neocortex. Coronal sections were cut from a rat brain fixed by perfusion as described in Materials and Methods. Sections at approximately bregma -3.0 to -3.5 (Paxinos and Watson, 1998) were double stained with antibodies against the pairs of proteins listed below. $A, B$, The rat thalamus double labeled with anti-citron $(A)$ and anti-GAD $(B)$ as described in Materials and Methods (20× lens objective). Arrowheads, Neurons labeled only with anti-citron antibodies and axons labeled only with anti-GAD antibodies. Very few GAD-positive neurons were seen in the central nuclei of the thalamus. $C, D$, Thalamus double labeled with anti-citron $(C)$ and anti-CaM kinase II $(D)$ as described in Materials and Methods $(20 \times$ lens objective). Arrows, Several neurons labeled with both antibodies. $E$, $F$, Sensory neocortex double labeled with anti-citron $(E)$ and anti-GAD $(F)$ as described in Materials and Methods $(63 \times$ lens objective). Arrows, A Cell labeled with anti-citron and anti-GAD antibodies; arrowheads, a cell and dendrites labeled with anti-citron antibodies but not anti-GAD antibodies. $G$, $H$, Sensory neocortex double labeled with anti-citron $(G)$ and anti-CaM kinase II $(H)$ as described in Materials and Methods (40× lens objective). Arrows, Neurons labeled with both antibodies; arrowheads, neurons labeled with anti-citron antibodies and unlabeled with anti-CaM kinase II antibodies. Scale bars, $25 \mu \mathrm{m}$. 

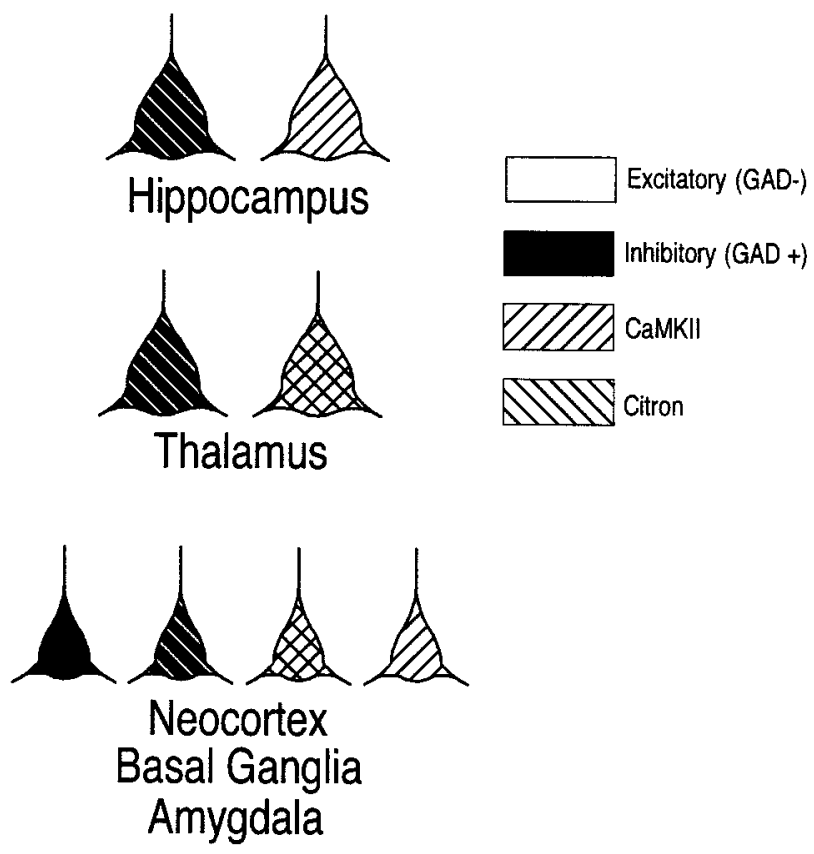

Figure 10. Cartoon representing the partitioning of citron and CaM kinase II among GABAergic and glutamatergic neurons in the brain. The schematic neuron does not represent any particular neuronal type; the shapes of citron-positive neurons vary widely in different brain regions.

a physical association between citron and PSD-95 in these neurons.

\section{Localization of citron in hippocampal cultures compared with that of other synaptic signaling molecules}

In contrast to citron, we found that the $\alpha$ subunit of CaM kinase II, a prominent component of PSDs in the forebrain, is expressed only in putative glutamatergic neurons and is not detectable in GABAergic neurons in the cultures (Fig. 6A). The $\alpha$ subunit of $\mathrm{CaM}$ kinase II was reported previously to be undetectable in GABAergic neurons in the monkey cerebral cortex (Jones et al., 1994) and in the rat hippocampus (Sik et al., 1998). Furthermore, cDNA encoding $\alpha \mathrm{CaM}$ kinase II is undetectable in GABAergic neurons in the monkey basal ganglia, thalamus, and hypothalamus (Benson et al., 1991). Therefore, the absence of $\alpha \mathrm{CaM}$ kinase II from GABAergic neurons may be a common feature of forebrain structures. Our results confirm that, in hippocampus, high expression of $\alpha \mathrm{CaM}$ kinase II occurs only in glutamatergic neurons, whereas high expression of citron occurs only in GABAergic neurons. Thus, the two signaling molecules are located in distinct populations of synapses.

The synaptic RasGAP protein, SynGAP, is also highly localized at glutamatergic synapses along dendrites (Chen et al., 1998) We double labeled cultured hippocampal neurons for citron and SynGAP and found that SynGAP is concentrated at glutamatergic synapses on excitatory neurons but is present in $<20 \%$ of GABAergic neurons (visualized by staining with citron) (Fig. $6 C, D$ ) and is undetectable in most GABAergic neurons (Fig. $6 C-F)$. The concentration of both SynGAP and CaM kinase II at glutamatergic synapses on excitatory neurons, colocalizing with NMDA receptors, is consistent with the hypothesis that SynGAP is an important target for phosphorylation by CaM kinase II after activation of NMDA receptors.

\section{In the hippocampus, citron is highly expressed in GABAergic neurons}

To check whether the segregation of citron and CaM kinase II into distinct neuronal types is also observed in the intact hippocampus, we double labeled sections of adult rat hippocampus (Figs. 7, 8). As in the cultures, citron staining was observed only in interneurons in hippocampus, identified by costaining with anti-GAD (Fig. $8 A-D$ ). The vast majority of GAD-positive neurons stain strongly with anti-citron antibodies. Immunoreactivity can be observed in a punctate pattern along the dendrites of these neurons (Fig. 8C,E), as expected if citron is located at synaptic sites. Similarly, nearly all citron-positive neurons stain with antiGAD antibodies. In contrast, anti- $\alpha \mathrm{CaM}$ kinase II labeled only the glutamatergic pyramidal neurons in hippocampus and did not label GABAergic interneurons that were labeled with citron (Sik et al., 1998) (Fig. 8E,F). Neurons coexpressing citron and GAD are scattered throughout the cell body and neuropil regions in areas CA1 (Fig. 8), CA3, and the dentate gyrus (data not shown) in a pattern described previously for inhibitory interneurons in the hippocampus (Freund and Buzsaki, 1996).

\section{Distribution of citron in brain regions other than hippocampus}

In contrast to hippocampal neurons, excitatory neurons in the major nuclei of the thalamus stain strongly with anti-citron antibodies and with antibodies against $\mathrm{CaM}$ kinase II but are unstained by anti-GAD antibodies (Fig. $9 A-D$ ). Inhibitory neurons in the reticular nucleus of the thalamus also stain strongly with anti-citron antibodies (data not shown). A subset of neurons in the neocortex are labeled with anti-citron antibodies (Fig. 9E-H), but the staining is generally weaker than in the thalamus. Approximately half of these neurons also stain with anti-GAD antibodies, indicating that they are GABAergic. The rest are labeled with antibodies against CaM kinase II, which is expressed only by glutamatergic neurons in the neocortex (Benson et al., 1991; Jones et al., 1994). Large apical dendrites labeled strongly with anti-citron antibodies course radially through layers 2-5 of the sensory cortex (Fig. 9E, $G$ ). Many of these appear to arise from the large pyramidal neurons in layers 5 and 6 (data not shown).

As in the neocortex, a subset of neurons in the basal ganglia and nuclei of the amygdala are labeled by anti-citron antibodies. Approximately half of these stain with anti-GAD antibodies and the other half with anti-CaM kinase II antibodies (data not shown). In the cerebellum, only very weak specific staining for citron was observed in the somata of Purkinje neurons and in the glomerular synapses of the granule cell layer (data not shown).

\section{DISCUSSION}

The small GTP-binding proteins Rho and Rac participate in regulation of the shape and dynamic movements of the cytoskeleton in a wide variety of cells (Hall, 1998). Here, we present evidence that in hippocampal neurons the putative Rho/Rac effector protein, citron, binds preferentially to the third PDZ domain of PSD-95 and is concentrated at postsynaptic sites at only those glutamatergic synapses made onto GABAergic neurons. The same selectively high concentration of citron observed in cultured GABAergic interneurons from the hippocampus is also evident in intact adult hippocampus. In contrast, citron is present at low levels in glutamatergic neurons in the hippocam- 


\begin{tabular}{llll}
\hline \multicolumn{4}{l}{$\begin{array}{l}\text { Table 2. Summary of the differential expression of signal transduction molecules and cytoskeletal } \\
\text { proteins at excitatory postsynaptic sites on glutamatergic and GABAergic neurons in the hippocampus }\end{array}$} \\
\begin{tabular}{llll} 
Postsynaptic signaling & Glutamatergic & GABAergic & \\
molecules & neurons & neurons & References \\
\hline Citron & - & + & \\
NR2B & + & + & \\
PSD-95 & + & + & Rao et al., 1998 \\
GKAP & + & ++ & \\
p135 SynGAP & + &,-+ & Jones et al., 1994; Sik et al., 1998 \\
CaM kinase II & + & - & Sik et al., 1998 \\
Calcineurin (phosphatase 2B) & + & - & Rao et al., 1998 \\
$\alpha$-Actinin & + & - &
\end{tabular} \\
\hline
\end{tabular}

pus. The relatively high concentration of citron at the excitatory postsynapse in GABAergic neurons suggests that the Rho and Rac GTP-binding proteins may play a special role at these synapses.

Citron was discovered in a yeast two-hybrid screen as a binding protein for the activated form of Rho and can bind to both activated Rho and activated Rac (Madaule et al., 1995). Citron is specifically expressed in neurons, whereas citron-K, a splice variant containing a serine/threonine protein kinase, is expressed in non-neuronal tissues (Madaule et al., 1998). In cultured Chinese hampster ovary cells, citron-K has been shown to mediate regulation by Rho of actin-based contractile events during cytokinesis (Madaule et al., 1998). Together, these observations suggest that citron likely plays a role in regulation of the actin cytoskeleton in neurons by the small GTP-binding proteins Rho or Rac. Expression by transgenesis of a constitutively active form of Rac in cerebellar Purkinje neurons of mice results in a reduction in the size of Purkinje dendritic spines and a dramatic increase in their number, suggesting that the Rac family of GTPases can regulate spine shape (Luo et al., 1996). The cytoskeleton of spines consists of actin filaments (Matus et al., 1982; Landis and Reese, 1983; Kaech et al., 1997). Thus, one interesting possibility is that citron may participate in regulation of the actin cytoskeleton at postsynaptic sites.

In contrast to citron, the $\alpha$ subunit of CaM kinase II is highly concentrated at glutamatergic synapses made onto glutamatergic neurons but is not detectable at synapses made onto GABAergic neurons (Benson et al., 1991; Sik et al., 1998) (Fig. 6A). SynGAP, a Ras GTPase-activating protein, is also highly concentrated at the same postsynaptic sites that contain CaM kinase II and is undetectable in synapses made onto most GABAergic neurons (Chen et al., 1998) (Fig. 5C-F). Citron and SynGAP contain the consensus motif for binding to PDZ domains of the scaffold protein PSD-95 and appear to interact with PSD-95 at synapses. PSD-95 itself is uniformly concentrated at excitatory synapses in both glutamatergic and GABAergic neurons (Fig. $5 E$ ). The results presented here support the notion that differential expression of PSD-95-binding proteins in different neurons helps to determine the composition of signal transduction complexes formed by association with PSD-95 at glutamatergic PSDs. The resulting distinct compositions of these complexes will likely define the nature of local biochemical signaling associated with activation of NMDA receptors.

The selective localization of citron described here suggests that in hippocampus PSDs of glutamatergic synapses made onto inhibitory interneurons contain cytoskeletal regulatory machinery that is not present at glutamatergic synapses made onto excitatory principal neurons. Furthermore, CaM kinase II is not detectable in these same PSDs but is present in the postsynaptic complex of excitatory synapses made onto glutamatergic neurons in the hippocampus (Benson et al., 1991; Sik et al., 1998). CaM kinase II can phosphorylate and regulate the GluRA/1 subunit of AMPAtype glutamate receptors (McGlade-McCulloh et al., 1993) and the synaptic Ras GTPase-activating protein SynGAP (Chen et al., 1998) and can phosphorylate the NR2A and NR2B subunits of the NMDA receptor (Omkumar et al., 1996). This regulation by CaM kinase II is absent from the postsynaptic side of glutamatergic synapses on hippocampal inhibitory neurons. Thus, the modes of regulation of synaptic structure (by citron) and of synaptic strength (by CaM kinase II or citron) at glutamatergic synapses will differ dramatically between excitatory and inhibitory neurons.

High citron expression only in GABAergic neurons appears to be a unique feature of the hippocampus. In other brain regions, such as the thalamus and cerebral cortex, citron and CaM kinase II are often found together in excitatory neurons (Figs. 9, 10). Thus, the composition of signal transduction machinery at the postsynaptic membrane of glutamatergic synapses varies among neurons throughout the brain in ways that cannot be classified simply. Furthermore, findings regarding the mechanisms of signal transduction and plasticity at hippocampal synapses may not always generalize to synapses in other areas of the brain.

Other postsynaptic cytoskeletal proteins are also located in different subpopulations of glutamatergic synapses in cultured hippocampal neurons. For example, GKAP, a protein of unknown function that binds specifically to the guanylate kinase domain of PSD-95, is more highly concentrated at glutamatergic synapses on GABAergic neurons than at those on glutamatergic neurons (Rao et al., 1998). In contrast, $\alpha$-actinin-2, which binds to NR1 competitively with calmodulin (Wyszynski et al., 1997), is found at glutamatergic synapses only in glutamatergic neurons but is not detectable at glutamatergic synapses on GABAergic neurons (Rao et al., 1998). Thus, the synaptic localization of CaM kinase II, SynGAP, and $\alpha$-actinin is complementary to that of citron and GKAP in cultured hippocampal neurons. The localization of postsynaptic molecules in the two classes of hippocampal neurons is summarized in Table 2.

Our data begin to provide a mechanistic explanation for the finding that different signal transduction events can be triggered by the entry of $\mathrm{Ca}^{2+}$ through NMDA receptors into glutamatergic versus GABAergic neurons in the hippocampus (see also, Sik et al., 1998). It appears that, in hippocampus, forms of synaptic 
plasticity, such as long-term potentiation (LTP) and long-term depression (LTD), will have quite different postsynaptic mechanisms in glutamatergic synapses made onto GABAergic interneurons when compared with glutamatergic synapses made onto excitatory neurons. In particular, the absence of expression of the $\alpha$ subunit of CaM kinase II in GABAergic neurons means that most mechanisms of LTP of glutamatergic synapses onto these neurons will be different from the well studied mechanisms in the Schaffer collateral pathway (Bliss and Collingridge, 1993). Indeed, direct NMDA receptor-dependent LTP does not occur at excitatory synapses on most classes of interneurons in the hippocampus in response to the usual induction stimuli (Maccaferri and McBain, 1996; Maccaferri et al., 1998; Sik et al., 1998). Furthermore, a novel form of LTD occurs at glutamatergic synapses on CA1 interneurons after tetanic stimulation (McMahon and Kauer, 1997). The mixing of a variety of synaptic regulatory mechanisms in different ways among neurons in different parts of the brain seems likely to provide rich variety in the mechanisms by which distinct areas of the brain process and encode information at synapses.

\section{REFERENCES}

Apperson ML, Moon I-S, Kennedy MB (1996) Characterization of densin-180, a new brain-specific synaptic protein of the O-sialoglycoprotein family. J Neurosci 16:6839-6852.

Benson DL, Isackson PJ, Hendry SHC, Jones EG (1991) Differential gene expression for glutamic acid decarboxylase and type II calciumcalmodulin-dependent protein kinase in basal ganglia, thalamus, and hypothalamus of the monkey. J Neurosci 11:1540-1564.

Bliss TVP, Collingridge GL (1993) A synaptic model of memory: longterm potentiation in the hippocampus. Nature 361:31-39.

Brenman JE, Christopherson KS, Craven SE, McGee AW, Bredt DS (1996) Cloning and characterization of postsynaptic density-93, a nitric oxide synthase interacting protein. J Neurosci 16:7407-7415.

Brewer GJ, Torricelli JR, Evege EK, Price PJ (1993) Optimized survival of hippocampal neurons in B27-supplemented Neurobasal, a new serum-free medium combination. J Neurosci Res 35:567-576.

Chen H-J, Rojas-Soto M, Oguni A, Kennedy MB (1998) A synaptic Ras-GTPase activating protein (p135 SynGAP) inhibited by CaM Kinase II. Neuron 20:895-904.

Chevesich J, Kreuz AJ, Montell C (1997) Requirement for the PDZ domain protein, INAD, for localization of the TRP store-operated channel to a signaling complex. Neuron 18:95-105.

Cho K-O, Hunt CA, Kennedy MB (1992) The rat brain postsynaptic density fraction contains a homolog of the Drosophila discs-large tumor suppressor protein. Neuron 9:929-942.

Craig AM, Blackstone CD, Huganir RL, Banker G (1994) Selective clustering of glutamate and gamma-aminobutyric acid receptors opposite terminals releasing the corresponding neurotransmitters. Proc Natl Acad Sci USA 91:12373-12377.

De Camilli P, Cameron R, Greengard P (1983) Synapsin I (protein I), a nerve terminal-specific phosphoprotein. I. Its general distribution in synapses of the central and peripheral nervous system demonstrated by immunofluorescence in frozen and plastic sections. J Cell Biol 96:1337-1354.

Erondu NE, Kennedy MB (1985) Regional distribution of type II $\mathrm{Ca}^{2+}$ / calmodulin-dependent protein kinase in rat brain. J Neurosci 5:3270-3277.

Freund TF, Buzsaki G (1996) Interneurons of the hippocampus. Hippocampus 6:347-470.

Hall A (1998) Rho GTPases and the actin cytoskeleton. Science 279:509-514.

Hunt CA, Schenker LJ, Kennedy MB (1996) PSD-95 is associated with the postsynaptic density and not with the presynaptic membrane at forebrain synapses. J Neurosci 16:1380-1388.

Irie M, Hata Y, Takeuchi M, Ichtchenko A, Toyoda A, Hirao K, Takai Y, Rosahl TW, Sudhof TC (1997) Binding of neuroligins to PSD-95. Science 277:1511-1515.

Ishizaki T, Maekawa M, Fujisawa K, Okawa K, Iwamatsu A, Fujita A, Watanabe N, Saito Y, Kakizuka A, Morii N, Narumiya S (1996) The small GTP-binding protein Rho binds to and activates a $160 \mathrm{kDa}$
Ser/Thr protein kinase homologous to myotonic dystrophy kinase. EMBO J 15:1885-1893.

Jones EG, Huntley GW, Benson DL (1994) Alpha calcium/calmodulindependent protein kinase II selectively expressed in a subpopulation of excitatory neurons in monkey sensory-motor cortex: comparison with GAD-67 expression. J Neurosci 14:611-629.

Kaech S, Fischer M, Doll T, Matus A (1997) Isoform specificity in the relationship of actin to dendritic spines. J Neurosci 17:9565-9572.

Kennedy MB (1993) The postsynaptic density. Curr Opin Neurobiol 3:732-737.

Kennedy MB (1997) The postsynaptic density at glutamatergic synapses. Trends Neurosci 20:264-268.

Kim E, Niethammer M, Rothschild A, Jan YN, Sheng M (1995) Clustering of shaker-type $\mathrm{K}+$ channels by interaction with a family of membrane-associated guanylate kinases. Nature 378:85-88.

Kim E, Naisbitt S, Hsueh YP, Rao A, Rothschild A, Craig AM, Sheng M (1997) GKAP, a novel synaptic protein that interacts with the guanylate kinase-like domain of the PSD-95/SAP90 family of channel clustering molecules. J Cell Biol 136:669-678.

Kim JH, Liao D, Lau L-F, Huganir RL (1998) SynGAP: a synaptic RasGAP that associates with the PSD-95/SAP90 protein family. Neuron 20:683-691.

Kistner U, Wenzel BM, Veh RW, Cases-Langhoff C, Garner AM, Appeltauer U, Voss B, Gundelfinger ED, Garner CC (1993) SAP90, a rat presynaptic protein related to the product of the Drosophila tumor suppressor gene $d l g$-A. J Biol Chem 268:4580-4583.

Kornau H-C, Schenker LT, Kennedy MB, Seeburg PH (1995) Domain interaction between NMDA receptor subunits and the postsynaptic density protein PSD-95. Science 269:1737-1740.

Kornau H-C, Seeburg PH, Kennedy MB (1997) Interaction of ion channels and receptors with PDZ domain proteins. Curr Opin Neurobiol 7:368-373.

Landis DMD, Reese TS (1983) Cytoplasmic organization in cerebellar dendritic spines. J Cell Biol 97:1169-1178.

Lau LF, Mammen A, Ehlers MD, Kindler S, Chung WJ, Garner CC, Huganir RL (1996) Interaction of the $N$-methyl-D-aspartate receptor complex with a novel synapse-associated protein, sap102. J Biol Chem 271:21622-21628.

Laube G, Röper J, Pitt JC, Sewing S, Kistner U, Garner CC, Pongs O, Veh RW (1996) Ultrastructural localization of Shaker-related potassium channel subunits and synapse-associated protein 90 to septate-like junctions in rat cerebellar Pinceaux. Mol Brain Res 42:51-61.

Leung T, Manser E, Tank L, Lim L (1995) A novel serine/threonine kinase binding the ras-related rhoA GTPase which translocates the kinase to peripheral membranes. J Biol Chem 270:27-34.

Leung T, Chen X-Q, Tan I, Manser E, Lim L (1998) Myotonic dystrophy kinase-related Cdc42-binding kinase acts as a Cdc42 effector in promoting cytoskeletal reorganization. Mol Cell Biol 18:130-140.

Luo L, Lee T, Tsai L, Tang G, Jan LY, Jan YN (1997) Genghis Khan (Gek) as a putative effector for Drosophila $\mathrm{Cdc} 42$ and regulator of actin polymerization. Proc Natl Acad Sci USA 94:12963-12968.

Luo LQ, Hensch TK, Ackerman L, Barbel S, Jan LY, Jan YN (1996) Differential effects of the rac GTPase on Purkinje cell axons and dendritic trunks and spines. Nature 379:837-840.

Maccaferri G, McBain CJ (1996) Long-term potentiation in distinct subtypes of hippocampal nonpyramidal neurons. J Neurosci 16:5334-5343.

Maccaferri G, Toth K, McBain CJ (1998) Target-specific expression of presynaptic mossy fiber plasticity. Science 279:1368-1370.

Madaule P, Furuyashiki T, Reid T, Ishizaki T, Watanabe G, Morii N, Narumiya S (1995) A novel partner for the GTP-bound forms of rho and rac. FEBS Lett 377:243-248.

Madaule P, Eda M, Watanabe N, Fujisawa K, Matsuoka T, Bito H, Ishizaki T, Narumiya S (1998) Role of citron kinase as a target of the small GTPase Rho in cytokinesis. Nature 394:491-494.

Matsui T, Amano M, Yamamoto T, Chihara K, Nakafuku M, Ito M, Nakano T, Okawa K, Iwamatsu A, Kaibuchi K (1996) Rho-associated kinase, a novel serine/threonine kinase, as a putative target for the small GTP binding protein Rho. EMBO J 15:2208-2216.

Matus A, Ackermann M, Pehling G, Byers HR, Fujiwara K (1982) High actin concentrations in brain dendritic spines and postsynaptic densities. Proc Natl Acad Sci USA 79:7590-7594.

McGlade-McCulloh E, Yamamoto H, Tan S-E, Brickey DA, Soderling TR (1993) Phosphorylation and regulation of glutamate receptors by calcium/calmodulin-dependent protein kinase II. Nature 362:640-642. 
McMahon LL, Kauer JA (1997) Hippocampal interneurons express a novel form of synaptic plasticity. Neuron 18:295-305.

Molloy SS, Kennedy MB (1991) Autophosphorylation of type II Ca ${ }^{2+}$ / calmodulin-dependent protein kinase in cultures of postnatal rat hippocampal slices. Proc Natl Acad Sci USA 88:4756-4760.

Moon IS, Apperson ML, Kennedy MB (1994) The major tyrosinephosphorylated protein in the postsynaptic density fraction is $N$-methylD-aspartate receptor subunit 2B. Proc Natl Acad Sci USA 91:3954-3958.

Muller BM, Kistner U, Veh RW, Cases-Langhoff C, Becker B, Gundelfinger ED, Garner CC (1995) Molecular characterization and spatial-distribution of sap97, a novel presynaptic protein homologous to sap90 and the Drosophila disks-large tumor-suppressor protein. J Neurosci 15:2354-2366.

Muller BM, Kistner U, Kindler S, Chung WJ, Kuhlendahl S, Fenster SD, Lau LF, Veh RW, Huganir RL, Gundelfinger ED, Garner CC (1996) Sap102, a novel postsynaptic protein that interacts with NMDA receptor complexes in vivo. Neuron 17:255-265.

Niethammer M, Kim E, Sheng M (1996) Interaction between the C terminus of NMDA receptor subunits and multiple members of the PSD-95 family of membrane-associated guanylate kinases. J Neurosci 16:2157-2163.

Niethammer M, Valtschanoff JG, Kapoor TM, Allison DW, Weinberg RJ, Craig AM, Sheng M (1998) CRIPT, a novel postsynaptic protein that binds to the third PDZ domain of PSD-95/SAP90. Neuron 20:693-707.

Omkumar RV, Kiely MJ, Rosenstein AJ, Min K-T, Kennedy MB (1996) Identification of a phosphorylation site for calcium/calmodulindependent protein kinase II in the NR2B subunit of the $N$-methy-Daspartate receptor. J Biol Chem 271:31670-31678.

Ou SK, Hwang JM, Patterson PH (1993) A modified method for obtaining large amounts of high-titer polyclonal Ascites fluid. J Immunol Methods 165:75-80.
Patton BL, Molloy SS, Kennedy MB (1993) Autophosphorylation of type II CaM kinase in hippocampal neurons: localization of phosphoand dephosphokinase with complementary phosphorylation sitespecific antibodies. Mol Biol Cell 4:159-172.

Paxinos G, Watson C (1998) The rat brain in stereotaxic coordinates. San Diego: Academic.

Peterson GL (1983) Determination of total protein. Methods Enzymol 91:95-119.

Rao A, Kim E, Sheng M, Craig AM (1998) Heterogeneity in the molecular composition of excitatory postsynaptic sites during development of hippocampal neurons in culture. J Neurosci 18:1217-1229.

Sik A, Hajos N, Gulacsi A, Mody I, Freund TF (1998) The absence of a major $\mathrm{Ca}^{2+}$ signaling pathway in GABAergic neurons of the hippocampus. Proc Natl Acad Sci USA 95:3245-3250.

Tejedor FJ, Bokhari A, Rogero O, Gorczyca M, Zhang JW, Kim E, Sheng M, Budnik V (1997) Essential role for dlg in synaptic clustering of Shaker $\mathrm{K}^{+}$channels in vivo. J Neurosci 17:152-159.

Tsunoda S, Sierralta J, Sun Y, Bodner R, Suzuki E, Becker A, Socolich M, Zuker CS (1997) A multivalent PDZ-domain protein assembles signalling complexes in a G-protein-coupled cascade. Nature 388:243-249.

Willott W, Balda MS, Fanning AS, Jameson B, Van Itallie C, Anderson JM (1993) The tight junction protein ZO-1 is homologous to the Drosophila discs-large tumor suppressor protein of septate junctions. Proc Natl Acad Sci USA 90:7834-7838.

Woods DF, Bryant PJ (1991) The discs-large tumor suppressor gene of Drosophila encodes a guanylate kinase homolog localized at septate junctions. Cell 66:451-464.

Wyszynski M, Lin J, Rao A, Nigh E, Beggs AH, Craig AM, Sheng M (1997) Competitive binding of $\alpha$-actinin and calmodulin to the NMDA receptor. Nature 385:439-442. 